long. $115^{\circ} \mathrm{W}$., where its depth is about $350 \mathrm{~m}$. The eastward flowing current is evident on this surface between lat. $2^{\circ} \mathrm{N}$. and $5^{\circ} \mathrm{N}$. in the west, from lat. $4^{\circ} \mathrm{N}$. to $8^{\circ} \mathrm{N}$. in the central ocean, and from lat. $\tilde{3}^{\circ}$ to $10^{\circ} \mathrm{N}$. at long. $120^{\circ} \mathrm{W}$., and is indicated on all of the Equapac sections and the pertinent Carnegie and Eastropic seetions all the way to the coast of America. Direct measurements ${ }^{4}$ made recently in the eastern Pacific have revealed that the eastward flow extends to at least $1,000 \mathrm{~m}$. at long. $107^{\circ} \mathrm{W}$.

There is evidence of an eastward flow at the sea surface south of the equator in the measurements of geostrophic flow made on the Equapac expeditions by the research vessels Orsom III (Institut Français d'Oceanie, New Caledonia, unpublished report) at lat. $9^{\circ} \mathrm{S}$. between long. $170^{\circ}$ and $180^{\circ} \mathrm{E}$., where speeds as high as $15 \mathrm{~cm}$./ $\mathrm{sec}$. are indicated, and by the Hugh M. Smith ${ }^{5}$ at the same latitude between long. $169^{\circ} \mathrm{W}$. and $135^{\circ} \mathrm{W}$., with speeds as high as $8 \mathrm{~cm} . / \mathrm{sec}$. indicated. Of the other Equapac lines, none reached so far as lat. $10^{\circ} \mathrm{S}$. except one at long. $164^{\circ}$ by the Horizon (Univ. of Calif. Scripps Inst. of Oceanogr., unpublished reports) and this was so near the Solomon Islands that the geostrophic calculations, which did indicate an eastward flow, might have other interpretations.

In a combination of stations from the Carnegie expedition and the Eastropic expeditions of 1955 and the Downwind expedition, a weak easterly flow may be interpreted so far east as long. $95^{\circ} \mathrm{W}$., but the observations are sparse and the feature is very poorly defined.

In the western Pacific, other evidence for the eastward flow at the sea surface may be found in various atlases prepared from observations of set and drift of vessels. The British average ${ }^{6}$ of set and drift for the seasons November-January and FebruaryApril indicate a weak eastward flow at lat. $10^{\circ} \mathrm{S}$. from long. $165^{\circ} \mathrm{E}$. to $140^{\circ} \mathrm{W}$. and from long. $165^{\circ} \mathrm{E}$. to $165^{\circ}$ W., respectively. No evidence is found in other months, and it is to be noted that the Equapac observations were made in August. The more recent Netherlands? monthly current charts show easterly flow along lat. $10^{\circ} \mathrm{S}$. from long. $165^{\circ}$ to $180^{\circ} \mathrm{E}$. in February, March and April. The American ${ }^{8}$ monthly charts show almost no evidence in any month.

The east-flowing current was encountered while studying the distribution of temperature, salinity, and oxygen along the density surface $\sigma_{t} 26 \cdot 81$, which lies in the intermediate water in the North Pacific and above the intermediate water of the South Pacific. This study is not yet completed, and further information about the flow at other depths and along other surfaces will be obtained as the work progresses.

Joseph L. REID, JUN.

Scripps Institution of Oceanography, University of California, La Jolla, California.

May 6.

1 Montgomery, R. B., Bull. Amer. Meteor. Soc., 18, 210 (1937).

2 Fleming, J. A., Ennis, C. C., Sverdrup, If. C., Eaton, S. L., and Hendrix, w. C., Carnegie Inst. Wash., Pub. No. 545, Oceanogr. I- $B$ (1945) King, J. E., Austin, T. S., and Doty, M. S., C.S. Fish Wildlife Serv
Spec. Sci. Rep., Fish. No. 201 (1957).

4 Knauss, J. A., and Pepin, R., Nature, 183, 380 (1959).

${ }^{5}$ Austin, T. S., U.S. Fish Wildlife Serv. Spec. Sei. Rep., Fish. No. 217 (1957).

${ }^{8}$ Mr.O. 435, Marine Div. Meteor. Off., Air Ministry, London (1939).

"Koninkiijk Nederlands Meteorologisch Institut, No. 124 (1949).

${ }^{8}$ C.S. Navy Hydrographic Off., Mise. No. 10,058 (1944).

\section{River Flow in Great Britain}

Prof. D. L. Linton, in his article on "River Flow in Great Britain, 1955-56"', has a map showing 'run-off deficit', defined as "Precipitation minus run-off",

While believing that maps of this parameter are much needed, it is doubtful whether the data from which they can at present be constructed for Great Britain are sufficient for drawing isopleth maps with any degree of accuracy. The network of gauging stations is too thin for it to be possible to assume that known errors in measurement of run-off, and in assessing rainfall over a whole catchment area, can cancel each other out. The estimation of precipitation is likely to be the most unreliable in large catchment areas of high relief, and these areas happen in general to be where the river-gauging network is particularly thin. These errors can alone well account for the apparently anomalous high run-off deficits in the Scottish Highlands, without necessarily invoking any other explanation.

Prof. Linton comments that the geographical variations of the fractions of precipitation disposed of by run-off and by evapo-transpiration are radically different, and adds: "it is doubted whether there has previously been any general appreciation of this difference by water engineers and others". There may not have been a "general appreciation" of this fact, but it has certainly been appreciated by some, who further appreciate that there is an important difference which is not revealed on his map, and which Prof. Linton does not mention, between different parts of the country. In fact of course the map, allowing for the errors mentioned above, does indicate the general geographical distribution of actual loss by evapo-transpiration; this however is in some parts of the country equal (in 1955-56, as in other years) to potential evapo-transpiration and in other parts not. In the rainfall year in question, the difference between actual and potential evapo-transpiration can safely be said to have been between 0 and 2 in. in many parts of western and highland Britain, while it almost certainly reached 12 in. in many parts of the south of England. Thus an 'actual loss' of 20 in. in Ross-shire (as shown on the run-off deficit map) would be a 'run-off deficit', with little or no "water deficit' while a similar run-off deficit in the south of England would be accompanied by a water deficit of 12 in. It needs to be emphasized that 'waterdeficit' is not the same as 'run-off deficit'; but values of both are needed, and there is need for a network of observations sufficient for both to be mapped. Consideration of both would reveal why there can be a high run-off defieit in the west Highlands, without any need to refer, as Prof. Linton does, to the large bodies of open water there; there are, after all, large bodies of open water in the English Lake District, which had a much lower run-off deficit on the $1955-56$ map.

Although, as Prof. Linton points out, there is a lack of gauging stations on the western seaboard, it is possible to extrapolate the map of 'discharge ratio' to the west coast, through observation or estimation of potential evaporation.

$$
\text { F. H. W. GREEN }
$$

The Nature Conservancy,

19 Belgrave Square, London, S.W.1.

${ }^{1}$ Nature, 183, 714 (1959). 